\title{
A Recent Study of the Relationship between the Precipitation Rate over Saudi Arabia in the Fall and Climatic Indices
}

\author{
Yehia Hafez (iD) and Abdulhaleem Labban (iD \\ Department of Meteorology, King Abdulaziz University, P.O. Box 80234, Jeddah 21589, Saudi Arabia \\ Correspondence should be addressed to Yehia Hafez; d_hafez@hotmail.com
}

Received 18 December 2019; Revised 17 March 2020; Accepted 7 July 2020; Published 20 July 2020

Academic Editor: Anthony R. Lupo

Copyright $\odot 2020$ Yehia Hafez and Abdulhaleem Labban. This is an open access article distributed under the Creative Commons Attribution License, which permits unrestricted use, distribution, and reproduction in any medium, provided the original work is properly cited.

\begin{abstract}
This paper presents a recent study of the relationship between precipitation rate (PR) over Saudi Arabia (SA) within the months of the fall season and climatic indices. The fall monthly PR data spanning the study period between 1948 and 2018 is considered. In addition, the monthly climatic index records (arctic oscillation (AO), global surface air temperature (GSAT), multivariate ENSO index (MEI), North Atlantic Oscillation (NAO) index, Nino 3.4 index, and Southern Oscillation Index (SOI)) for the fall months were also considered. The statistical trend, anomaly, and correlation analyses are applied in this study. The results reveal that the sweeping changes in PR show generally positive trends throughout the fall seasons of the past decades. Moreover, the climatic indices have an effect on the PR over SA within the fall months and season. During the study period, the most substantial relationship recorded, with an inverse correlation of -0.7 , is between the PR over SA and the climatic index of GSAT for September and October. Moreover, there is a clear correlation of +0.5 between the PR over SA and the ENSO and Nino 3.4 index for October and November.
\end{abstract}

\section{Introduction}

Recently, Saudi Arabia (SA) has suffered from an extreme precipitation variation, mainly during the fall season. However, the SA climatic zone is that of a dry climate. The distribution, quantity, and duration of precipitation in arid and semiarid zones were considered to be highly variable [1-6]. The northern regions of SA, the region around the Central North, and the southwest areas of SA recorded the highest level of precipitation $(171.5 \mathrm{~mm})$ during the year of 1982.

Meanwhile, the southeast areas of SA are arid. The southwest region of SA experiences precipitation throughout the twelve months of each year [7]. In fact, the SA climate varies significantly, according to the geography and climate yeartide of the annual cycle, and is influenced by circulations in the atmosphere $[4,6,8-10]$. Actually, the regional circulation pattern of precipitation for the duration of the fall over SA was precisely related to the same regional circulation and distribution during the spring season [11].
Several global scientific works presented in the literature consider the teleconnections between precipitation and climatic indices. In particular, the authors in [12] used the Southern Oscillation Index (SOI) to enhance precipitation forecast and manage agricultural water in the Republic of Ghana. The authors of [13] studied how to predict rainfall over Australia by the use of the SOI phase. Recently, there are several scientific literatures challenge the teleconnections between the precipitations and large-scale phenomena like as atmospheric blocking systems [14-16].

From previous research works in [17-20], it was found that there is robust proof for the essence of the link between climatic conditions and the variability of the Arctic oscillation ( $\mathrm{AO})$. It appears that there is a connection between $\mathrm{AO}$ and the climatic conditions for many areas in the Northern Hemisphere [21-28]. Besides, weather variations and climatic conditions and North Atlantic Oscillation (NAO) variations are significantly and positively correlated [29-31]. Both AO and NAO variations play significant roles in understanding the physical and dynamical mechanisms of 
the variations of the Northern Hemisphere [32]. The authors of [33] realized that the seasonal and interannual changes in the average air temperature of SA show a warming period that began in the last years of the twentieth century. This temperature variability follows global warming signs.

Furthermore, it appears that the sturdy variability in temperature over SA was mostly related to the North Atlantic Oscillation indices, majorly throughout the winter season. Mostly, El Nino Southern Oscillation (ENSO) index, $\mathrm{AO}$, and NAO indices take significant roles in the continuous temperature rise over SA $[4,6,7,34]$. Additionally, global mean surface temperature (GSAT) change was analyzed by many organizations, including the NASA Goddard Institute for Space Studies. These studies found that global warming is enduring persistently. The authors of [31] noted that there is a significant, substantial connection between the global mean surface air temperature and precipitation over Europe. In the same manner, the authors of [35] found that the ENSO phenomenon generates a significant proportion of short-term climate variability globally. The relationship between ENSO and precipitation in South East Queensland, Australia, has been studied. The authors of [36] found that the Southern Oscillation Index (SOI) and rainfall amounts could be predicted in the short term using the analysis of time series methods. The authors of [6] found that SA climate parameters, temperature, and PR were correlated with and controlled by the Oceanic Nino Index (ONI).

The present work aims to uncover the relationship between the PR variability over SA in the fall months and season and the climatic indices throughout the study period (1948-2018).

\section{Materials and Methods}

2.1. Data. National Center for Atmospheric Research (NCAR) and National Centers for Environmental Prediction (NCEP) reanalysis program makes use of a perfect analysis system to assimilate records with a resolution $n$ of $2.5 \times 2.5$ degree lat/long grid, by making use of previous data between 1948 and 2018. The NCEP/NCAR reanalysis 1 is the source of Saudi Arabian PR used in the present work. However, the NCEP/NCAR reanalysis 1 project is using a state-of-the-art analysis/forecast system to perform data assimilation using past data from 1948 to the present time. A large subset of this data is available from the Physical Sciences Division (PSD) in its original four times daily format and as daily averages. This data was obtained eight times in a day as per model, since the inputs available in that era were available at $3 Z, 9 Z$, $15 Z$, and $21 Z$, whereas the four times daily data has been available as $0 \mathrm{Z}, 6 \mathrm{Z}, 12 \mathrm{Z}$, and $18 \mathrm{Z}$. These latter times were forecasted and the combined result of this early era is eight times daily. The NCEP/NCAR reanalysis 1 data was obtained from https://www.esrl.noaa.gov/psd/data/gridded/data. ncep.reanalysis.html.

The monthly statistics set of the PR over the region of SA for the study period of 1948 to 2018 for the fall months (September-October-November) was considered. Moreover, the monthly datasets for the climatic indices (AO, GSAT, MEI, NAO, Nino 3.4, and SOI) for the fall months of the study period (1948-2018) are used. This data was provided with the support of the NOAA, ESRL PSD, OAR, Boulder, Colorado, USA, and [37]. In the present work, the domain of the NCEP data for the PR over the Arabian Peninsula, including $\mathrm{SA}$, was considered to extend over the area of $12^{\circ} \mathrm{N}-32^{\circ} \mathrm{N}, 33^{\circ} \mathrm{E}-60^{\circ} \mathrm{E}$. Figure 1 shows a map, including the Arabian Peninsula and Saudi Arabia.

2.2. Methodology. Time series and anomaly analysis methods were used to analyze the monthly and seasonal PR over SA throughout the study period (1948-2018). The climatic average values of the $\mathrm{PR}$ were considered throughout the time between 1981 and 2010. However, this data used for the time between 1981 and 2010 is the recent climatic mean taken from climate-related research works. The anomaly of precipitation $(A)$ was calculated as the difference between the precipitation amount $(A)$ and its climatic mean $(\hat{A})$ for each grid point in the domain of the area of study during that time (1948-2018). Additionally, linear correlation methods were employed to study the teleconnections between the PR over SA in the fall season and the climatic indices through the period of 1948-2018 used for the current evaluations. The methodology of Monte Carlo has been used [38]. Statistically, based on this methodology, a correlation of 0.2 would be significant for 66 degrees of freedom. In addition to that, the linear correlation method according to $[38,39]$ is used. The statistical significance was determined using the Kendall-tau test. According to that test, a trend was deemed to be "statistically significant" if it has at least $90 \%$ significance.

2.2.1. Computation of the Fall Seasonal Means. A fall seasonal mean of PR for every grid point of the domain of SA $(9 \times 12$-degree lat/long grids) was calculated, whereas 9 grid points from $12^{\circ}$ north to $32^{\circ}$ north for latitudes and 12 grid points from $33^{\circ}$ east to $60^{\circ}$ east for longitudes have been used. Fall PR seasonal means over SA were calculated. Both were computed by the use of NCEP/NCAR reanalysis monthly figures for the fall season ((September + October + November)/ three). The climatic PR means for the period of study (1981-2010) were also calculated. The monthly datasets of the climatic indices (AO, GSAT, MEI, NAO, Nino 3.4, and SOI) over the fall months of the study period (1948-2018) were analyzed in the similar method. The interactive plotting and analysis NCEP and NCAR software packages were applied in these computations.

\subsubsection{Local Significance and Computation of Correlation} Patterns. The set data for monthly and seasonal PR averages at every grid point correlated with the earlier climatic indices. $t$-tests were performed on the correlation of every grid point for local significance using [40], allowing sequential autocorrelation as per [38] technique. To evaluate the correlation, we apply the Monte Carlo methodology. The field significance statistic is deemed to be area-weighted average of the absolute correlation of a given correlation map. The 


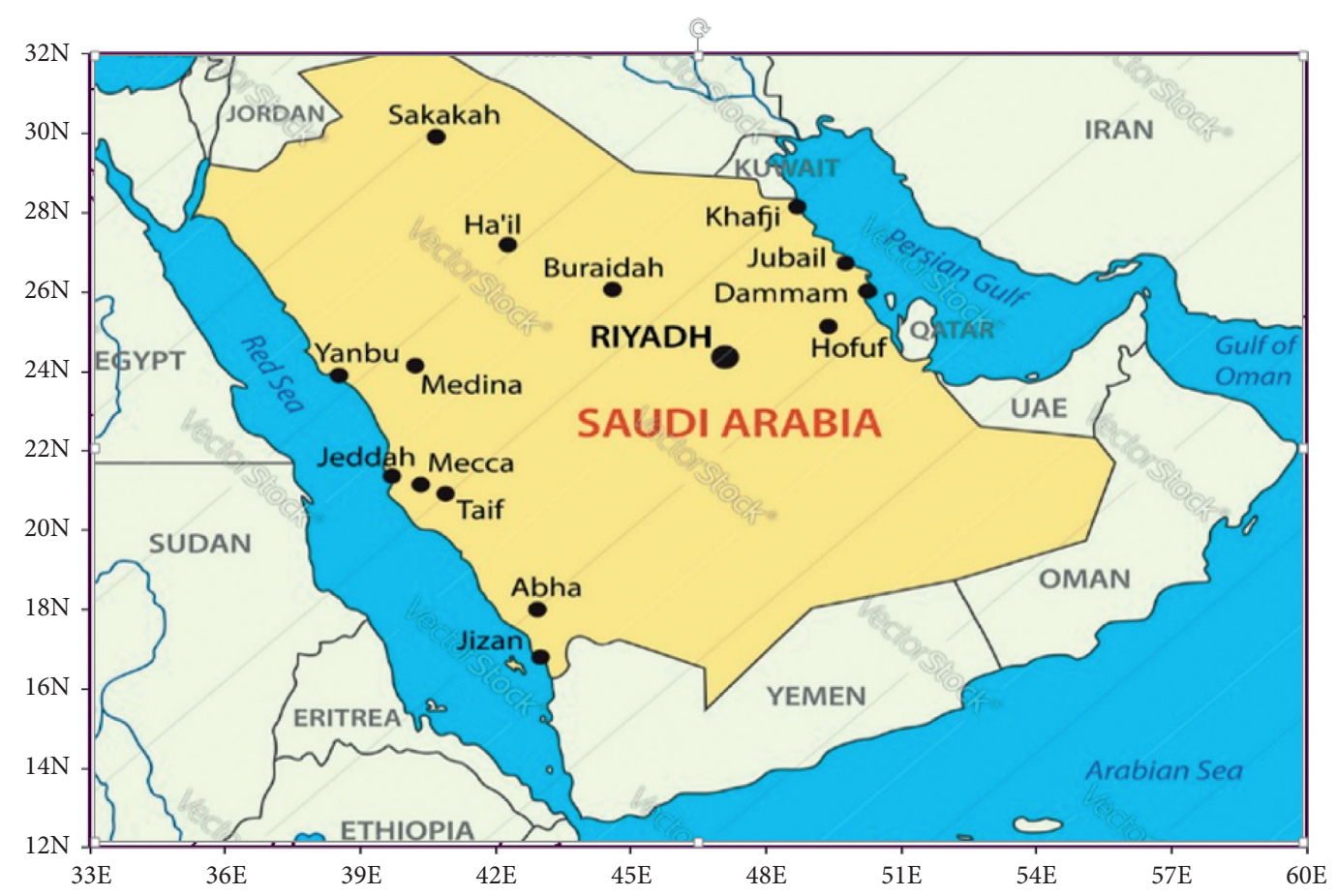

Figure 1: The map of the Arabian Peninsula, including Saudi Arabia.

field-significance threshold equals the 95th percentile of a 1000-member Monte Carlo population.

\section{Results and Discussion}

\subsection{Results}

3.1.1. Variability of PR over SA in the Fall Season throughout the Period of 1948-2018. The NCEP/NCAR reanalysis shows that all datasets of the fall PR over SA for between the years 1948 and 2018 were scrutinized using the anomaly technique. The results showed the following:

(1) Time series analysis of the September monthly PR over SA shows that the PR is above its normal values from 1950 to 1966 . The maximum positive anomaly is $1.1 \mathrm{~mm} /$ day in 1960 . After that period, the amounts of PR oscillate around its normal value until 2008. For the period of 2009-2018, the PR remains above its normal values. The polynomial trend analysis of the September PR shows that it increased over the past 10 years with a positive trend, as illustrated in Figure 2.

(2) Analysis of the October PR illustrates that the extreme values for almost all of the years throughout 1948-2018 are positive extreme values. PR analysis shows a positive trend for the period of 1993-2018, as shown in Figure 3.

(3) From the examination of the November precipitation rate, it is clear that there are three intervals. The first one spans from the year 1948 to the year 1972 with years of positive anomalies that are greater than those with negative anomalies. The maximum positive anomaly $(+1.7 \mathrm{~mm} /$ day $)$ occurred in 1957 . The second interval, from 1973 to 1995, has a PR that is less than its normal value. The third interval (1974-2018) was characterized by positive PR anomalies, with a significant positive trend throughout the period of 1993-2018; see Figure 4.

(4) The PR amounts in the fall season over SA mainly look like the variability of the November monthly PR throughout the study period (1948-2018). However, there is a positive PR trend from 1992 to 2018 , as is clear from Figures 4-5.

3.1.2. Study of the Teleconnection between the PR over SA and Climatic Indices in Fall. Composite means of the correlation coefficients of the monthly reanalysis datasets of the PR over $\mathrm{SA}$ and the climatic indices (AO, GSAT, MEI, NAO, Nino3.4, and SOI) were studied for the months of September, October, and November and fall season from 1948 to 2018. The composite means of the correlation coefficient of the PR over SA and climatic indices were then evaluated for the study period. The results showed the following:

(1) In September, there is no doubt that there are weighty strong negative correlation coefficients between the PR over SA and the GSAT. The value of this correlation coefficient reached -0.7 over the east and east-central regions of SA during the research period (1948-2018). Figure 6(b) and Table 1 show the results. Moreover, for September, it appears that there is a clear positive correlation between the PR over SA and Nino 3.4. However, this correlation coefficient $(+0.4)$ was mainly found over the west and 


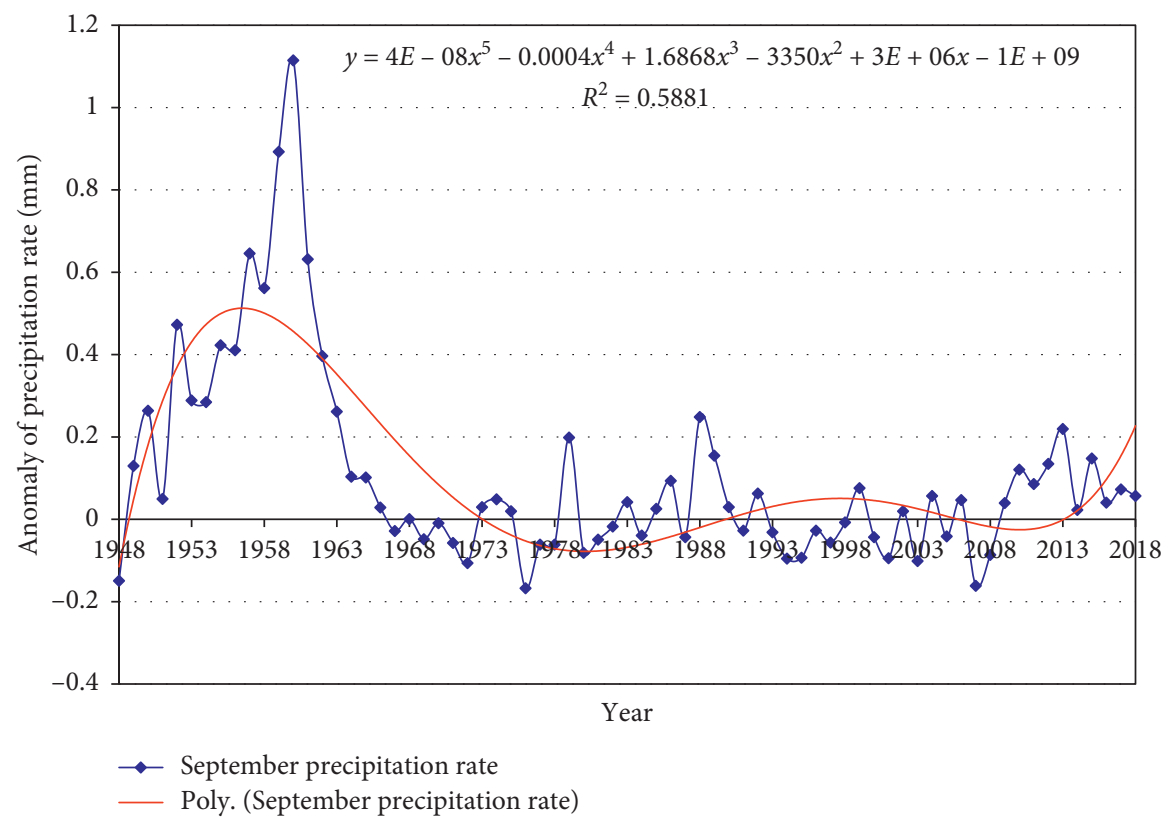

FIgURE 2: Time series of PR anomaly (mm/day) and its polynomial trend over the Arabian Peninsula, including SA in the month of September throughout the period (1948-2018).

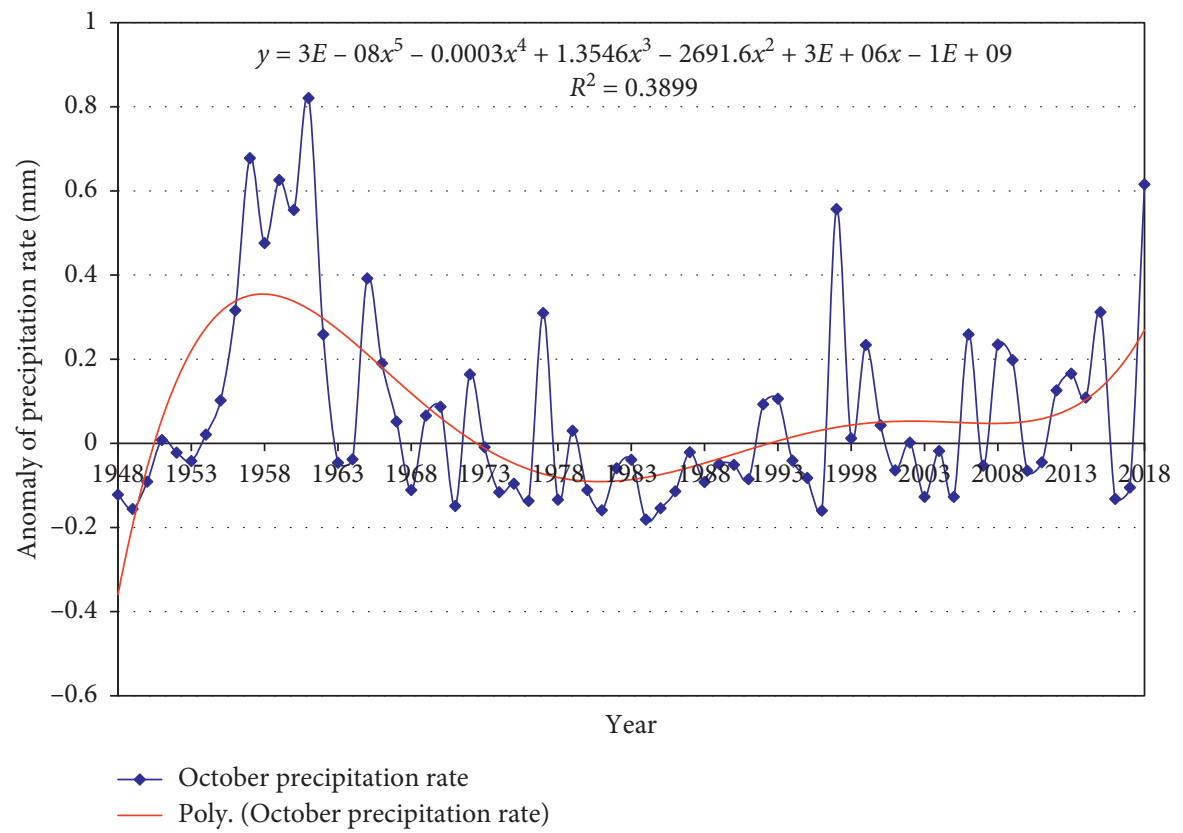

FIgURE 3: Time series of PR anomaly ( $\mathrm{mm} /$ day) and its polynomial trend over the Arabian Peninsula, including SA in the month of October throughout the period (1948-2018).

the north-central regions of SA during the study period, as shown in Figure 6(e) and Table 1. Meanwhile, there is a nonsignificant correlation between September PR over SA and the other climatic indices AO, MEI, NAO, and SOI (see Figures 6(a), 6(c), 6(d), and 6(f) and Table 1).

(2) For the month of October, the results revealed a strong negative correlation coefficient $(-0.7)$ between the PR over the south-west of SA and GSAT during the study period as shown in Figure 7(b) and Table 1. Moreover, there is a strong correlation with the AO, MEI, SOI, and Nino 3.4 indices, with correlation coefficients of $+0.4,+0.4,-0.4$, and +0.5 , respectively, as shown in Figures $7(\mathrm{a}), 7(\mathrm{c}), 7(\mathrm{f})$, and 7(e) and Table 1.

(3) In November, the highest significant correlation coefficient $(+0.5)$ with the MEI index was present over almost all of SA throughout the study period as 


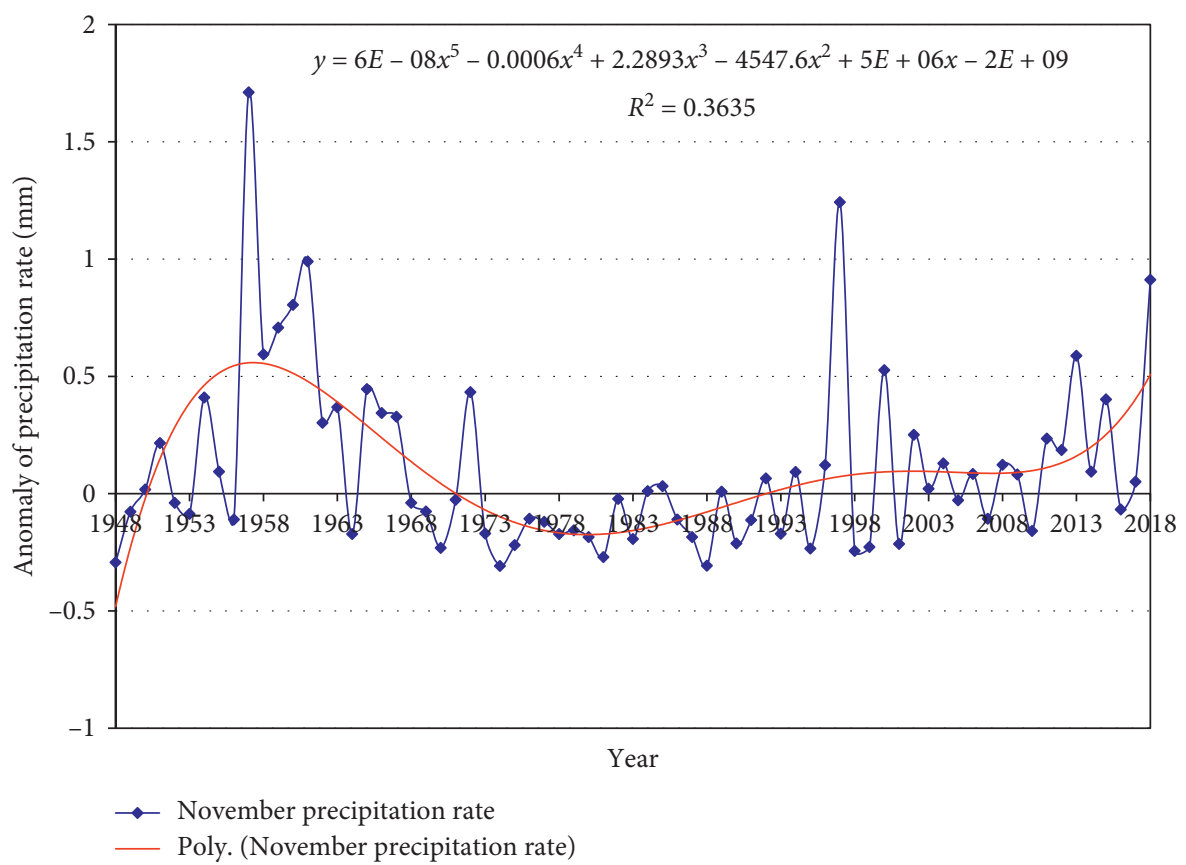

Figure 4: Time series of PR anomaly (mm/day) and its polynomial trend over the Arabian Peninsula, including SA in November throughout the period (1948-2018).

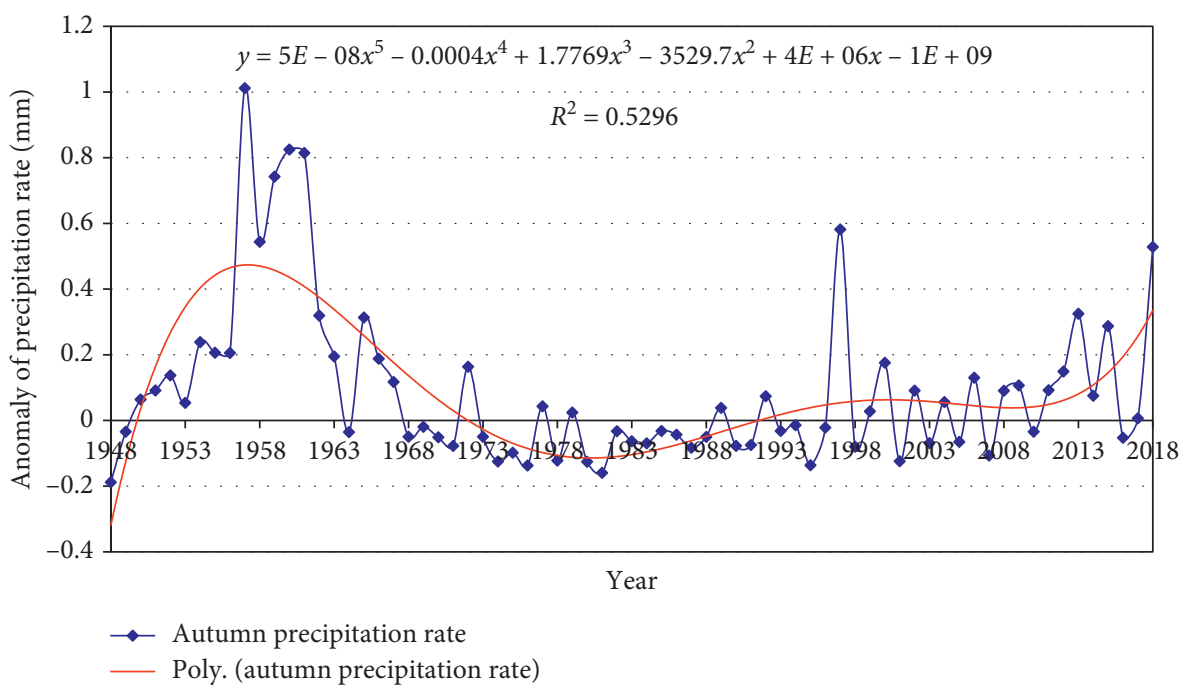

FIgURE 5: Time series of PR anomaly for PR ( $\mathrm{mm} /$ day) and its polynomial trend over the Arabian Peninsula, including SA for the fall seasons throughout the period (1948-2018).

illustrated from Figure $8(\mathrm{c})$ and Table 1. The correlation coefficients for November illustrate that there is a significant correlation $(+0.4)$ between the PR over SA and the AO, GSAT, and Nino 3.4 indices over distinct parts of SA, as shown in Figures 8(a), $8(\mathrm{~b})$, and $8(\mathrm{e})$ and Table 1. Meanwhile, there is no significant correlation with $\mathrm{NAO}$ and $\mathrm{SOI}$ as is clear from Figures 8(d) and 8(f) and Table 1.

(4) For the fall season, the MEI and Nino 3.4 indices have the maximum positive correlation coefficients $(+0.5)$ over almost all regions of SA, as shown in Figures 9(c) and 9(e) and Table 1. Considerable correlation coefficient values of +0.4 and -0.4 are also observed for the GSAT and SOI indices, respectively, over the central parts of SA throughout the study period, as shown in Figures $9(\mathrm{~b})$ and $9(\mathrm{f})$ and Table 1. Meanwhile, there is no significant correlation with $\mathrm{AO}$ and NAO as obtained from Figures 9(a) and 9(d) and Table 1.

(5) The lowest correlation coefficient recorded overall was that of the NAO index $(-0.2)$. 


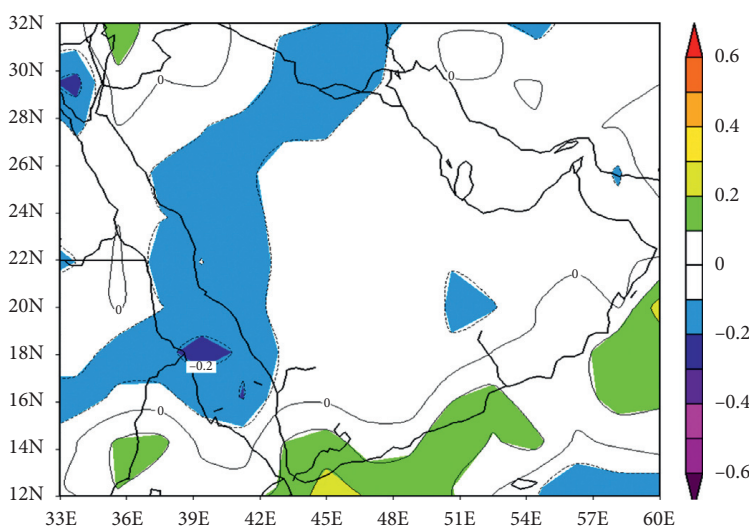

(a)

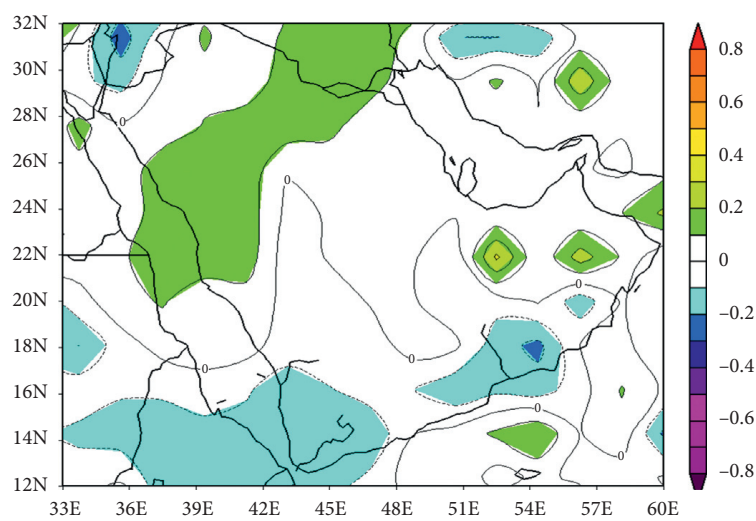

(c)

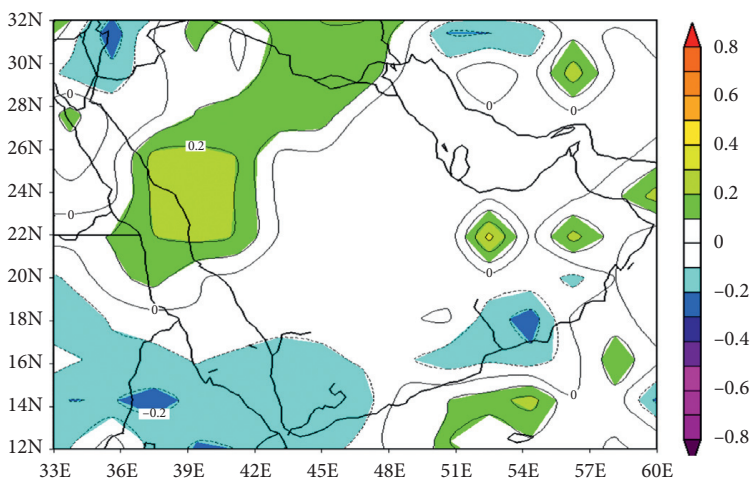

(e)

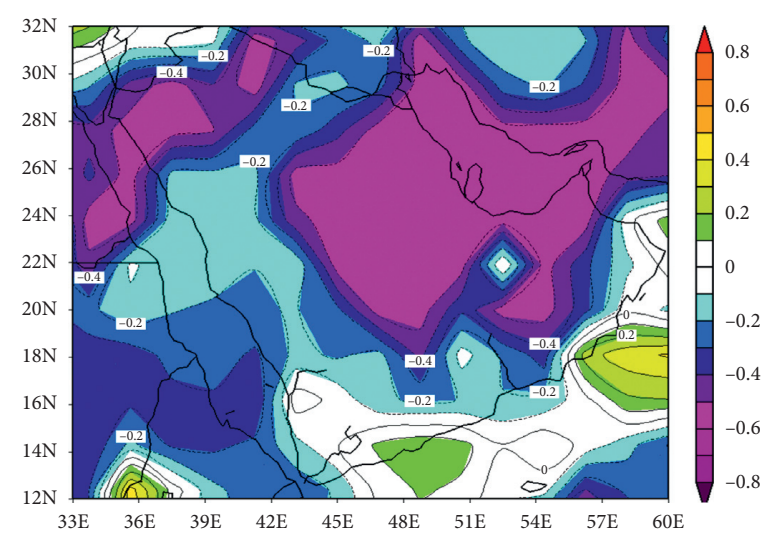

(b)

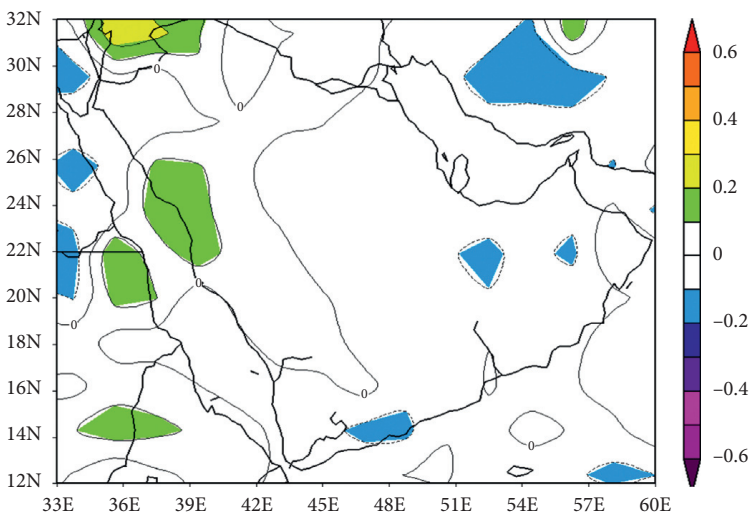

(d)

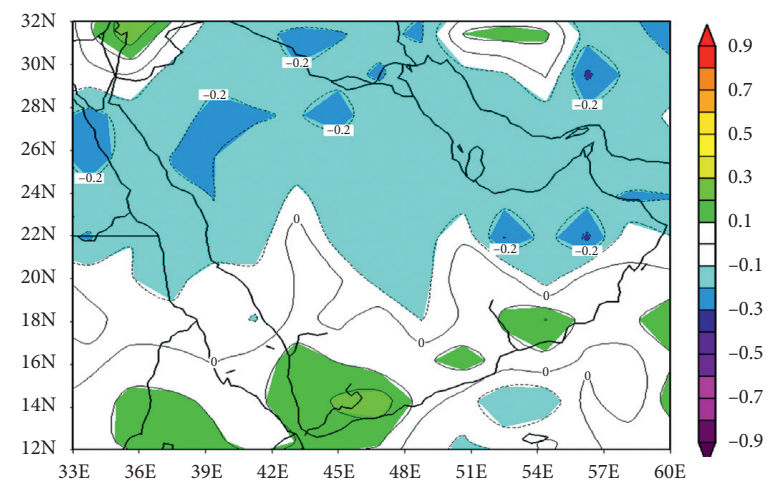

(f)

FIgure 6: The distribution of the correlation coefficients between the PR over the Arabian Peninsula, including SA, and the climatic indices for September during the study period (1948-2018). (a) AO. (b) GSAT. (c) MEI. (d) NAO. (e) Nino 3.4. (f) SOI (NCEP/NCAR Reanalysis NOAA/ESRL Physical Sciences Division).

TABLE 1: The matrix of correlation coefficients between the PR over SA and the chosen climatic indices for specific locations over SA during the fall seasons of the study period (1948-2018).

\begin{tabular}{lcccc}
\hline Correlation coefficient & \multicolumn{3}{c}{ Maximum correlation coefficient and its location in SA } \\
Climatic index & September & October & November & Fall season \\
\hline AO & -0.2 & +0.4 & -0.4 & -0.3 \\
Region & W and NC & E & and NW & NW and W \\
GSAT & $-0.7^{*}$ & $-0.7^{*}$ & +0.4 & +0.4 \\
Region & E and EC & SE & C and SW & C \\
MEI & +0.2 & +0.4 & $+0.5^{* *}$ & $+0.5^{* *}$ \\
\hline
\end{tabular}


TABLE 1: Continued.

\begin{tabular}{lcccc}
\hline Correlation coefficient & \multicolumn{3}{c}{ Maximum correlation coefficient and its location in SA } \\
Climatic index & September & October & November & FLall season \\
\hline Region & $\mathrm{W}$ and NC & $\mathrm{N}$ and NW & -0.3 & ALMOST \\
NAO & +0.2 & -0.3 & $\mathrm{NW}$ andW & -0.2 \\
Region & $\mathrm{W}$ & $\mathrm{C}$ & +0.4 & W \\
Nino 3.4 & +0.4 & $+0.5^{* *}$ & ALMOST & $+0.5^{* *}$ \\
Region & $\mathrm{W}$ and NC & $\mathrm{N}$ and NW & -0.3 & ALMOST \\
SOI & -0.3 & -0.4 & $\mathrm{~W}$ and C & -0.4 \\
Region & $\mathrm{N}$ & $\mathrm{N}$ and NW & C \\
\hline
\end{tabular}

${ }^{*}$ Significance level $>99 \% .{ }^{* *}$ Significance level $>95 \%$. N: North SA, S: South SA, W: West SA, E: East SA, C: Central SA, ALMOST: almost all of SA.

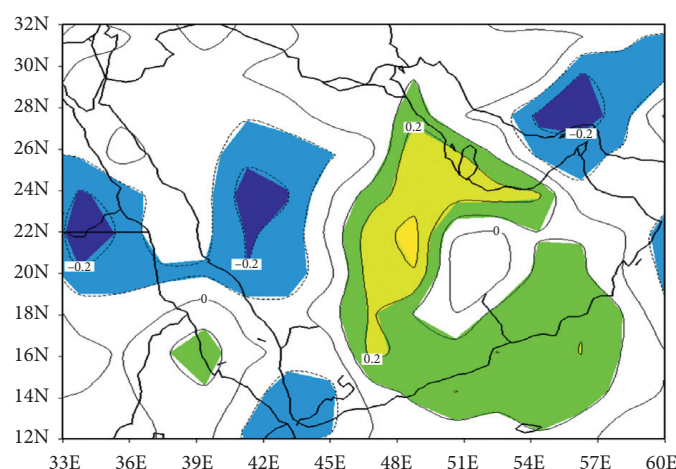

(a)

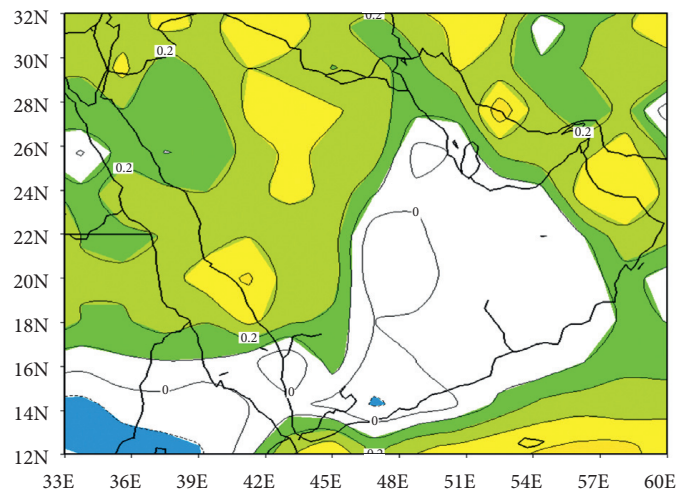

(c)

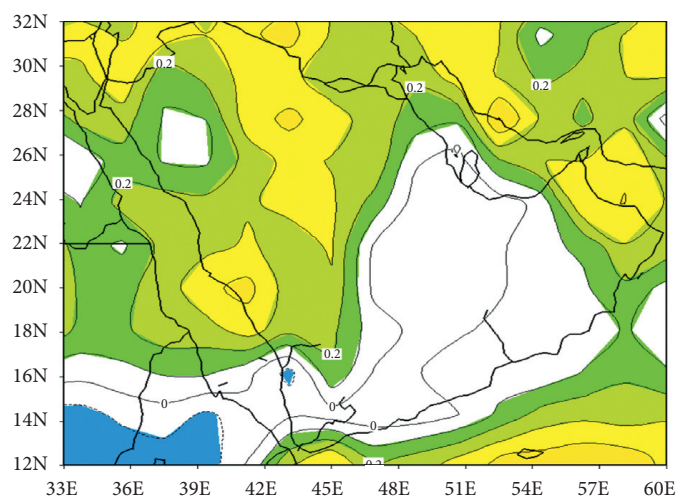

(e)

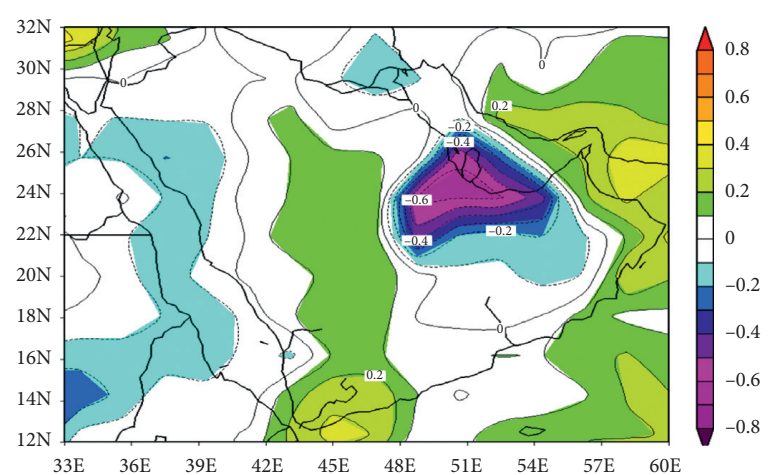

(b)

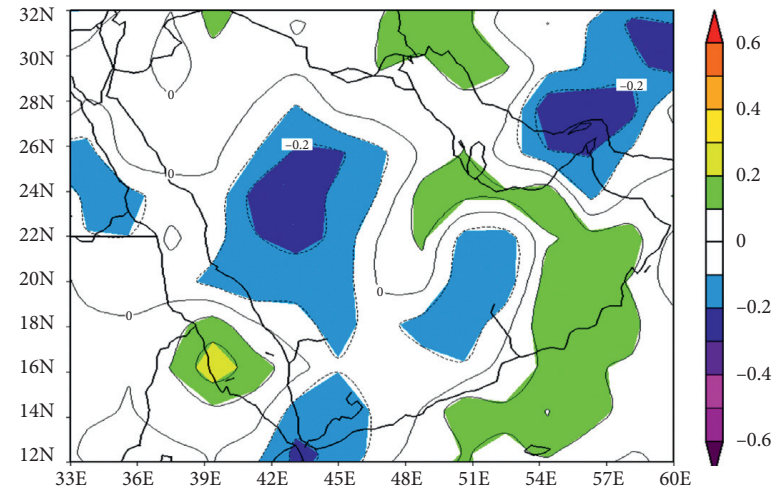

(d)

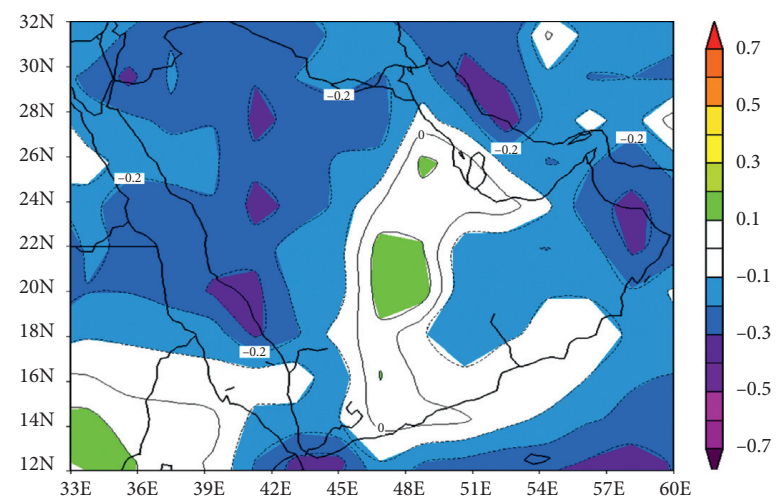

(f)

Figure 7: The distribution of the correlation coefficients between the PR over the Arabian Peninsula, including SA, and the climatic indices for October during the study period (1948-2018). (a) AO. (b) GSAT. (c) MEI. (d) NAO. (e) Nino 3.4. (f) SOI (NCEP/NCAR Reanalysis NOAA/ESRL Physical Sciences Division). 


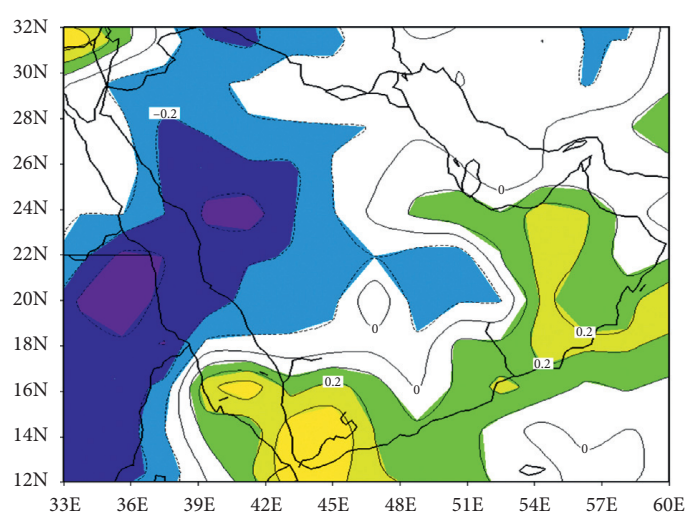

(a)

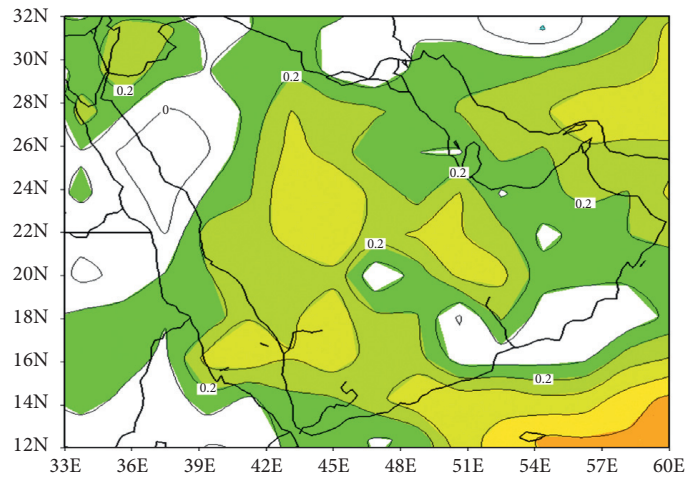

(c)

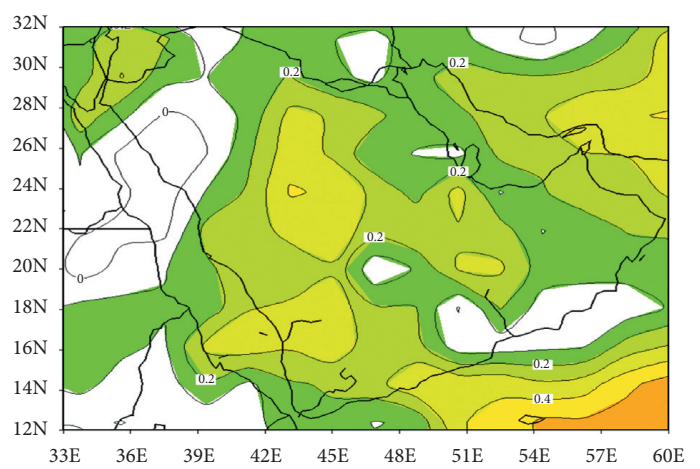

(e)
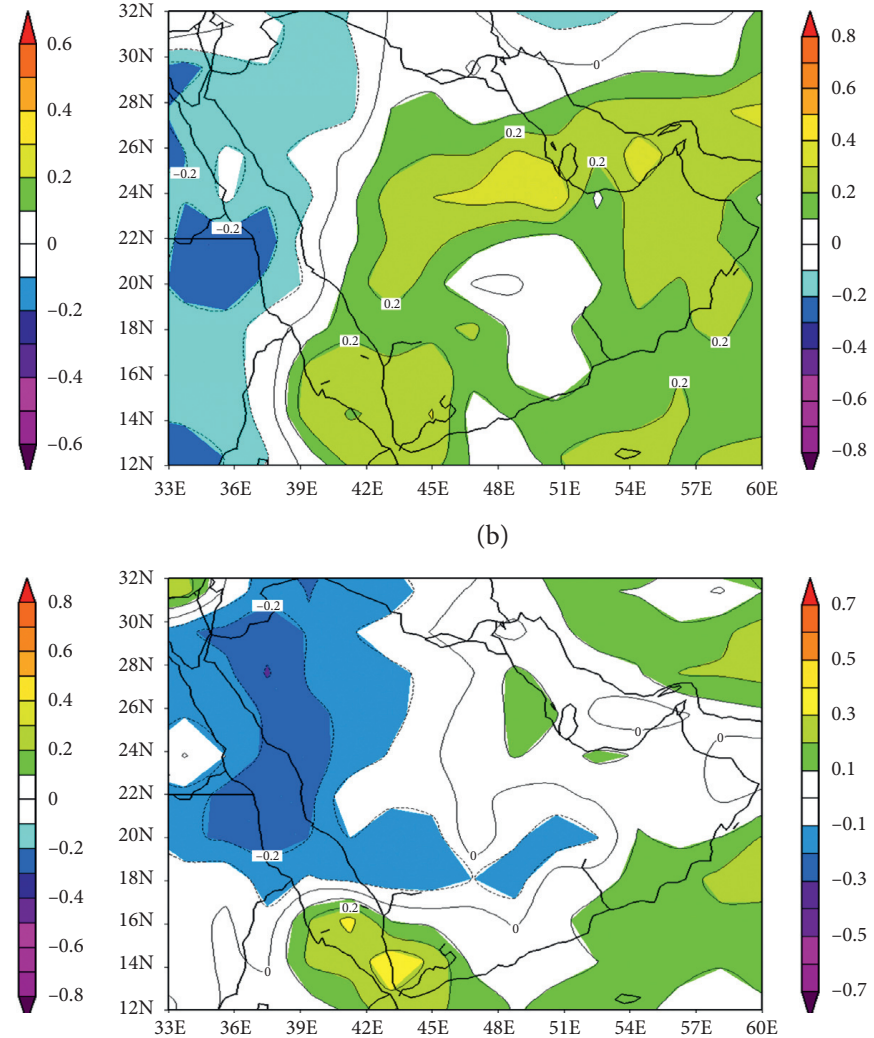

(d)
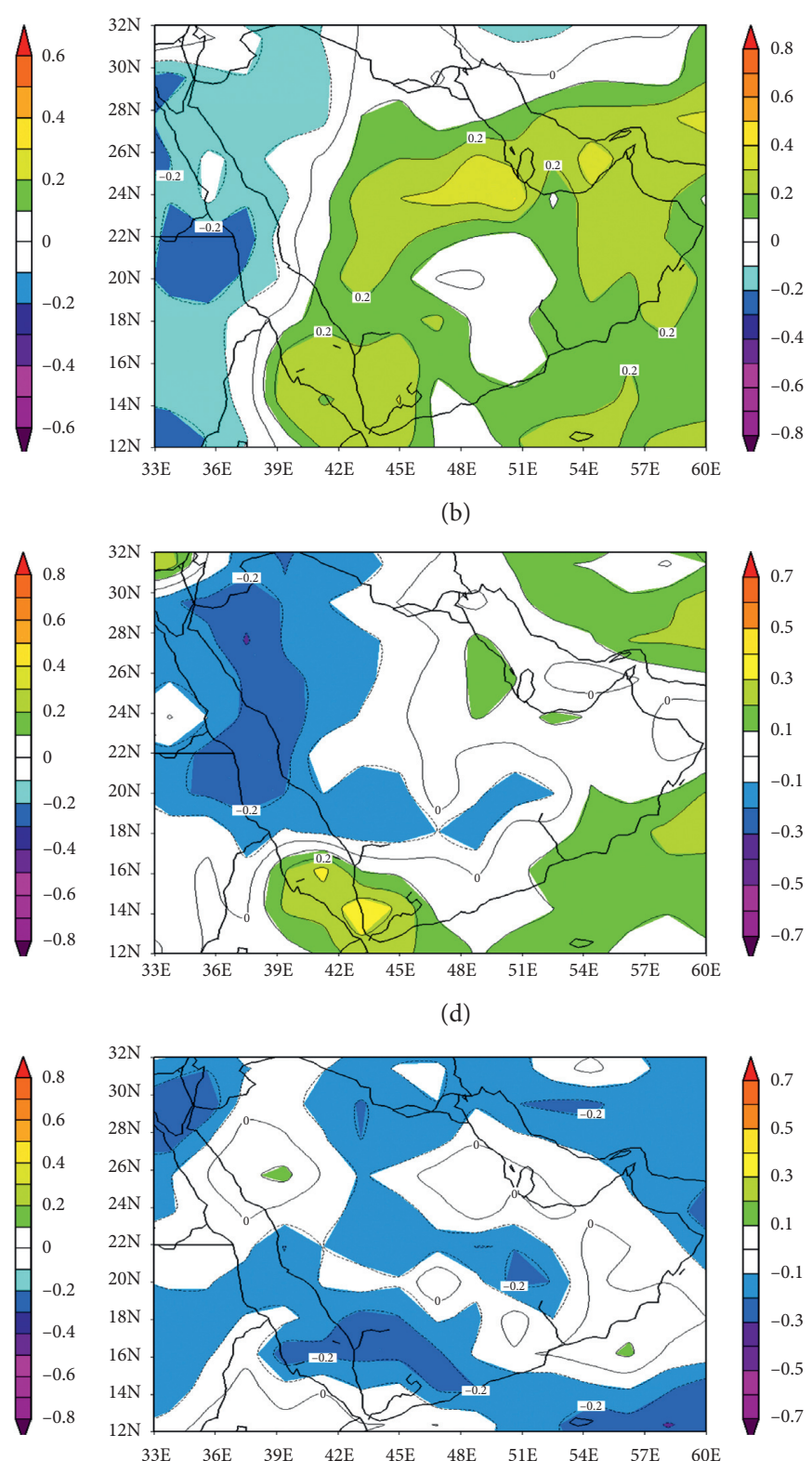

(b)

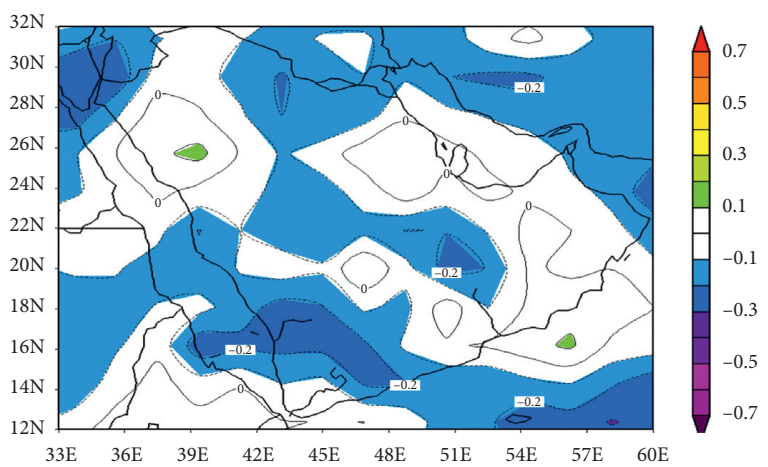

(f)

FIgure 8: The distribution of the correlation coefficients between the PR over the Arabian Peninsula, including SA, and the climatic indices for November during the study period (1948-2018). (a) AO. (b) GSAT. (c) MEI. (d) NAO. (e) Nino 3.4. (f) SOI (NCEP/NCAR Reanalysis NOAA/ESRL Physical Sciences Division).

3.2. Discussion. The present work provides a teleconnection study between PR over SA in the fall season and the climatic indices. According to [8], there are extreme changes in temperature and precipitation in the Arab region. Some significant relationships were found between climate extremes with ENSO over the eastern part of the Arab region. The authors of [4] studied the rainfall features and variations over SA. It was found that the climate of SA was instructed by ENSO, NAO, and SOI. The authors of [6] studied the relationship between the Oceanic Nino Index (ONI) and temperature and precipitation rates over SA. It was found that the SA climatic parameters, temperature, and precipitation rates were controlled by ONI. From the present analysis of PR variability of the fall through the period of study (1948-2018), it is clear that the PR over SA varies dramatically from month to month throughout the fall season during the study period. It is obvious that each month (September, October, and November) has unique PR variations. Generally speaking, the trend of PR variations is a positive trend through the last decade. Through the present work, the teleconnection between the PR over SA and the climatic indices (AO, GSAT, MEI, NAO, Nino 3.4, and SOI) has been studied. It becomes clear that the PR over SA in fall season was affected significantly by the global warming and 


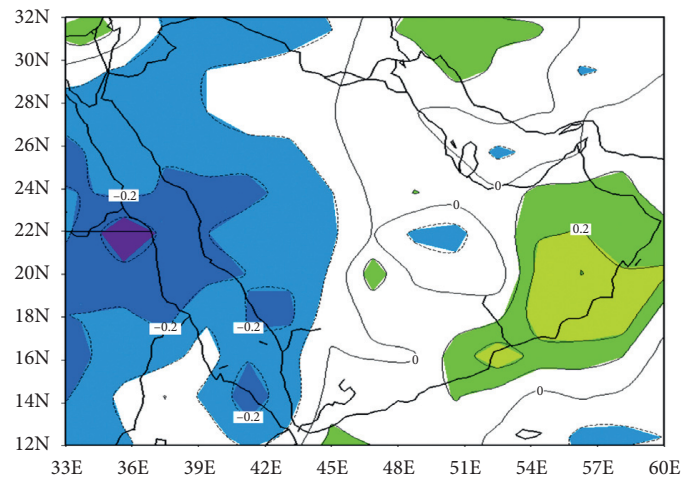

(a)

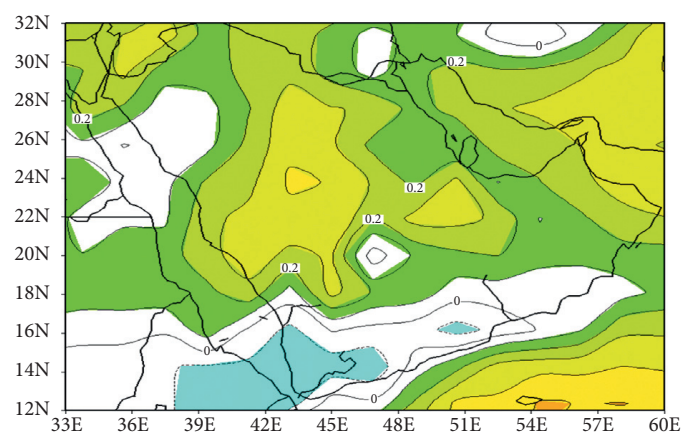

(c)

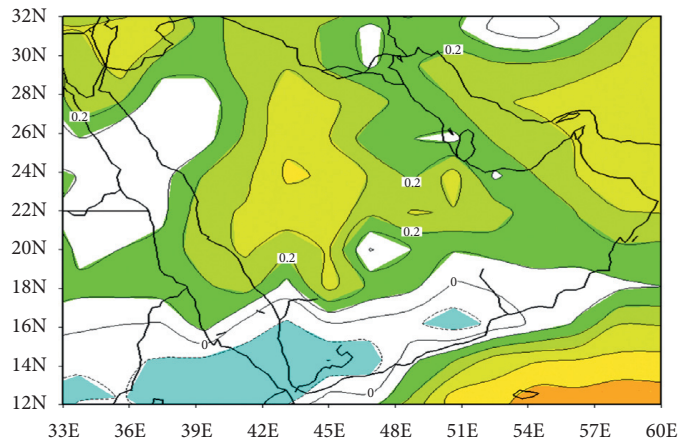

(e)
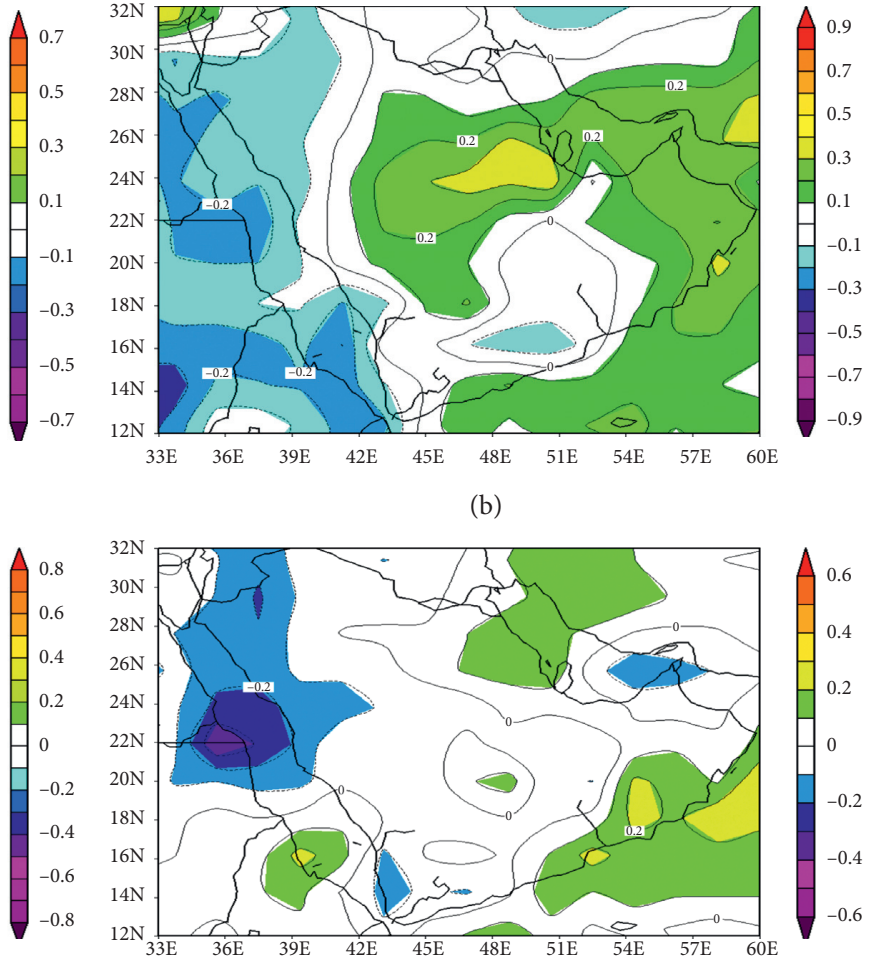

(d)
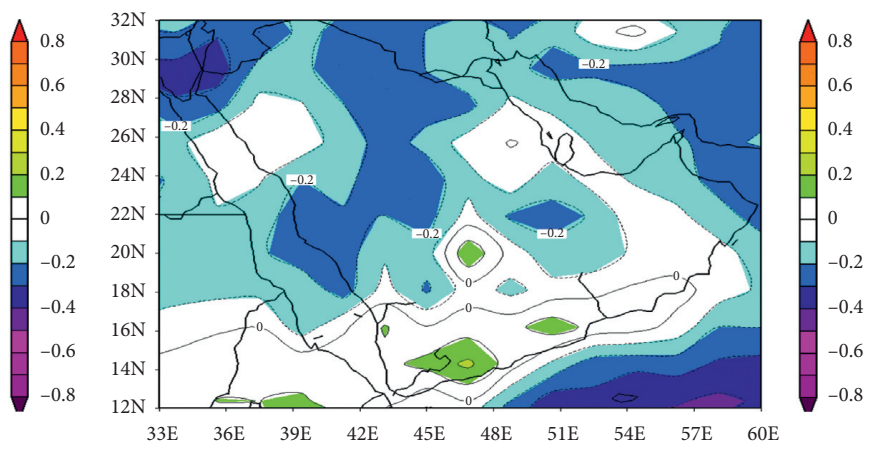

(f)

FIgURE 9: The distribution of the correlation coefficients between the PR over the Arabian Peninsula, including SA, and the climatic indices for the fall season during the study period (1948-2018). (a) AO. (b) GSAT. (c) MEI. (d) NAO. (e) Nino 3.4. (f) SOI (NCEP/NCAR Reanalysis NOAA/ESRL Physical Sciences Division).

large-scale atmospheric circulation. Meanwhile, there is a very strong significant negative correlation coefficient $(-0.7)$ between PR over SA and the GSAT for the month of September. In addition, there is a significant positive correlation coefficient $(+0.4)$ between PR over SA and Nino 3.4 for the month of September. For the month of October, there is an outstanding negative correlation coefficient $(-0.7)$ between PR over SA and the GSAT. In addition to that, the month of October PR over SA was influenced by several climatic indices (AO, MEI, SOI, and Nino 3.4). However, it becomes clear that the month of November PR over SA was related to climatic indices (MEI, AO, GSAT, and Nino 3.4). For the fall season, it was noticed that MEI, Nino 3.4, GSAT, and SOI are affecting the PR over SA throughout the period of study (1948-2018).

\section{Conclusions}

The teleconnection between the precipitation and climatic indices has attracted the attention of researchers of climate and climatic changes for decades. This paper investigated a teleconnection study between PR over SA in the fall season and the climatic indices (AO, GSAT, MEI, NAO, Nino 3.4, and SOI) throughout the period of study (1948-2018). The results revealed that $\mathrm{PR}$ over SA has an outstanding significant correlation with the climatic indices. Finally, one can conclude that the climatic indices affect and control the PR over several regions of SA in fall season. However, the results obtained through the present work aid the future research regarding rainfall forecast in SA by using the assessed indices for prediction models. 


\section{Data Availability}

NCEP/NCAR reanalysis datasets of monthly precipitation rate are available at https://psl.noaa.gov/data/composites/ datasets.html. A monthly/seasonal meantime series of the precipitation rate from the NCEP reanalysis dataset is available at https://psl.noaa.gov/cgi-bin/data/timeseries/ timeseries1.pl. The datasets of monthly climate indices (AO, GSAT, MEI, NAO, Nino 3.4, and SOI) are available at https://psl.noaa.gov/data/climateindices/. The datasets of linear correlations in Atmospheric Seasonal/Monthly Averages of climatic indices with weather elements are available at NOAA physical science laboratory.

\section{Conflicts of Interest}

The authors declare that they have no conflicts of interest.

\section{Acknowledgments}

The authors would like to acknowledge the NOAA/ESRL Physical Sciences Division for providing data and images on its website (http://www.esrl.noaa.gov/psd/).

\section{References}

[1] M. Abdullah and M. Al-Mazroui, "Climatological study of the southwestern region of Saudi Arabia. I. Rainfall analysis," Climate Research, vol. 9, no. 3, pp. 213-223, 1998.

[2] A. Y. Kwarteng, A. S. Dorvlo, and G. T. Vijaya Kumar, "Analysis of a 27-year rainfall data (1977-2003) in the Sultanate of Oman," International Journal of Climatology, vol. 29, no. 4, pp. 605-617, 2009.

[3] M. El-Nesr, A. Abdulrahman, and M. Abu-Zreig, "Analysis of evapotranspiration variability and trends in the arabian Peninsula," American Journal of Environmental Sciences, vol. 6, no. 6, pp. 535-547, 2010.

[4] H. Hasanean and M. Almazroui, "Rainfall: features and variations over Saudi Arabia, A review," Climate, vol. 3, no. 3, pp. 578-626, 2015.

[5] S. Hag-elsafi and M. El-Tayib, "Spatial and statistical analysis of rainfall in the Kingdom of Saudi Arabia from 1979 to 2008," Weather, vol. 71, no. 10, pp. 262-266, 2016.

[6] Y. Hafez, "Study on the relationship between the oceanic Nino index and surface air temperature and precipitation rate over the kingdom of Saudi Arabia," Journal of Geoscience and Environment Protection, vol. 4, no. 5, pp. 146-162, 2016.

[7] M. Almazroui, M. N. Islam, P. D. Jones, H. Athar, and M. A. Rahman, "Recent climate change in the Arabian Peninsula: seasonal rainfall and temperature climatology of Saudi Arabia for 1979-2009," Atmospheric Research, vol. 111, pp. 29-45, 2012.

[8] M. G. Donat, T. C. Peterson, M. Brunet et al., "Changes in extreme temperature and precipitation in the Arab region: long-term trends and variability related to ENSO and NAO," International Journal of Climatology, vol. 34, no. 3, pp. 581592, 2014.

[9] I.-S. Kang, I. U. Rashid, F. Kucharski, M. Almazroui, and A. K. Alkhalaf, "Multidecadal changes in the relationship between ENSO and wet-season precipitation in the Arabian Peninsula," Journal of Climate, vol. 28, no. 12, pp. 4743-4752, 2015.
[10] Y. Hafez, "A recent study concerning the climatic variability over the kingdom Saudi Arabia for the period 1948-2018," Journal of Geoscience and Environment Protection, vol. 7, no. 8, pp. 268-289, 2019.

[11] A. Mashat and H. Abdel Basset, "Analysis of rainfall over Saudi Arabia," Journal of King Abdulaziz University: Metrology, Environment and Arid Land Agricultural Sciences, vol. 22, no. 592, pp. 1-40, 2011.

[12] S. G. K. Adiku and R. C. Stone, "Using the Southern Oscillation Index for improving rainfall prediction and agricultural water management in Ghana," Agricultural Water Management, vol. 29, no. 1, pp. 85-100, 1995.

[13] D. H. Cobon and N. R. Toombs, "Forecasting rainfall based on the Southern Oscillation Index phases at longer lead-times in Australia," The Rangeland Journal, vol. 35, no. 4, pp. 373-383, 2013.

[14] B. Efe, A. R. Lupo, and A. Deniz, "The relationship between atmospheric blocking and precipitation changes in Turkey between 1977 and 2016," Theoretical and Applied Climatology, vol. 138, no. 3-4, pp. 1573-1590, 2019.

[15] W. Huang, Z. Yang, X. He et al., "A possible mechanism for the occurrence of wintertime extreme precipitation events over South China," Climate Dynamics, vol. 52, no. 3-4, pp. 2367-2384, 2019.

[16] Y. Y. Hafez, H. M. Hasanean, and M. A. Hussein, “A blocking diagnosis method and its application in the blocking system over Europe in the Summer of 2010," Asia-Pacific Journal of Atmospheric Sciences, vol. 1, pp. 1-16, 2020.

[17] E. N. Lorenz, "Seasonal and irregular variations of the Northern Hemisphere sea-level pressure profile," Journal of Meteorology, vol. 8, no. 1, pp. 52-59, 1951.

[18] J. E. Kutzbach, "Large-scale features of monthly mean Northern Hemisphere anomaly maps of sea-level pressure," Monthly Weather Review, vol. 98, no. 9, pp. 708-716, 1970.

[19] D. W. J. Thompson and J. M. Wallace, "The Arctic Oscillation signature in the wintertime geopotential height and temperature fields," Geophysical Research Letters, vol. 25, no. 9, pp. 1297-1300, 1998.

[20] D. W. J. Thompson and J. M. Wallace, "Annular modes in the extratropical circulation. Part I: month-to-month variability*," Journal of Climate, vol. 13, no. 5, pp. 1000-1016, 2000.

[21] D. Gong and S. Wang, "Definition of Antarctic oscillation index," Geophysical Research Letters, vol. 26, no. 4, pp. 459462, 1999.

[22] D. W. J. Thompson, J. M. Wallace, and G. C. Hegerl, “Annular modes in the extratropical circulation. Part II: Trends," Journal of Climate, vol. 13, no. 5, pp. 1018-1036, 2000.

[23] Y. P. Zhou, R. W. Higgins, and H. K. Kim, Relationships between El Niño-Southern Oscillation and the Arctic Oscillation: A Climate-Weather Link, National Centers for Environmental Information, Asheville, NC, USA, 2001.

[24] K. M. Hines and D. H. Bromwich, "A pole to pole west Pacific atmospheric teleconnection during August," Journal of Geophysical Research: Atmospheres, vol. 107, no. D18, 2002.

[25] D.-Y. Gong and C.-H. Ho, "Arctic oscillation signals in the East Asian summer monsoon," Journal of Geophysical Research: Atmospheres, vol. 108, 2003.

[26] J. E. Overland and M. Wang, "The Arctic climate paradox: the recent decrease of the Arctic Oscillation," Geophysical Research Letters, vol. 32, no. 6, 2005.

[27] J. Sun and H. Wang, "Relationship between Arctic oscillation and Pacific decadal oscillation on decadal timescale," Chinese Science Bulletin, vol. 51, no. 1, pp. 75-79, 2006. 
[28] K.-S. Choi and H.-R. Byun, "Possible relationship between western North Pacific tropical cyclone activity and Arctic Oscillation," Theoretical and Applied Climatology, vol. 100, no. 3-4, pp. 261-274, 2010.

[29] J. M. Wallace and D. S. Gutzler, "Teleconnections in the geopotential height field during the Northern Hemisphere winter," Monthly Weather Review, vol. 109, no. 4, pp. 784-812, 1981.

[30] J. W. Hurrell, "Decadal trends in the North Atlantic Oscillation: regional temperatures and precipitation," Science, vol. 269, no. 5224, pp. 676-679, 1995.

[31] Y. Y. Hafez, "The teleconnection between the global mean surface air temperature and precipitation over Europe," International Journal of Meteorology, vol. 33, no. 331, p. 230, 2008.

[32] M. H. P. Ambaum, B. J. Hoskins, and D. B. Stephenson, "Arctic oscillation or North Atlantic oscillation?" Journal of Climate, vol. 14, no. 16, pp. 3495-3507, 2001.

[33] M. Almazroui, "Temperature variability over Saudi Arabia and its association with global climate indices," Journal of King Abdulaziz University: Metrology, Environment and Arid Land Agricultural Sciences, vol. 23, no. 582, pp. 1-48, 2011.

[34] I. U. Rashid, M. Almazroui, S. Saeed, and R. M. Atif, "Analysis of extreme summer temperatures in Saudi Arabia and the association with large-scale atmospheric circulation," Atmospheric Research, vol. 231, p. 104659, 2020.

[35] L. Goddard and M. Dilley, "El niño: catastrophe or opportunity," Journal of Climate, vol. 18, no. 5, pp. 651-665, 2005.

[36] G. A. Tularam, "Relationship between El niño southern oscillation index and rainfall (Queensland, Australia)," International Journal of Sustainable Development and Planning, vol. 5, no. 4, pp. 378-391, 2010.

[37] E. Kalnay, M. Kanamitsu, R. Kistler et al., "The NCEP/NCAR 40-year reanalysis project," Bulletin of the American Meteorological Society, vol. 77, 1996.

[38] R. E. Livezey and W. Y. Chen, "Statistical field significance and its determination by Monte Carlo techniques," Monthly Weather Review, vol. 111, no. 1, pp. 46-59, 1983.

[39] P. Diaconis and B. Efron, "Computer-intensive methods in statistics," Scientific American, vol. 248, no. 5, pp. 116-130, 1983.

[40] J. Phillips, How to Think about Statistics, Macmillan, New York, NY, USA, 1999. 